\title{
Модель выбора процедуры государственных закупок на примере лекарственных препаратов
}

\author{
А. М. Жемкова ${ }^{1 凶}$ \\ ${ }^{1}$ Институт прикладных экономических исследований, Российская академия народного хозяйства \\ и государственной службы при Президенте Российской Федерации, проспект Вернадского, 82, стр. 1, \\ 119571, Москва, Российская Федерация
}

Для цитирования: Жемкова А. М. Модель выбора процедуры государственных закупок на примере лекарственных препаратов // Вестник Воронежского государственного университета. Серия: Экономика и управление. 2020. №. 3. С. 48-59. DOI: 10.17308/econ.2020.3/3104

Предмет. Результаты теоретических и эмпирических работ свидетельствуют о том, что для простых и стандартизированных товаров аукцион является наиболее эффективной и надежной процедурой для отбора лучшего поставщика, однако, когда качество закупаемого товара принимает особое значение, простые ценовые критерии для определения поставщика, используемые при проведении электронных аукционов, могут оказаться неэффективными. В статье оценивается предпочтительность для заказчиков (российских больниц) процедур для закупки лекарственных препаратов.

Цель. Статья ставит целью проверить, действительно ли аукционы могут оказаться не самой предпочтительной для заказчика процедурой закупки сложных товаров (на примере лекарственных препаратов). Для этого в работе проводится оценка факторов (в том числе - качественных характеристик товара и отношения заказчика к качеству), влияющих на выбор заказчиком закупочной процедуры, и далее - анализ влияния этих факторов и выбора процедуры на уровень закупочных цен.

Методология. В процессе исследования эффективности процедур для закупок лекарственных препаратов применяются методы качественного и количественного анализа. Эмпирическую базу составляют данные с сайта единой информационной системы в сфере госзакупок.

Результаты. Проведен эмпирический анализ процесса выбора заказчиком процедуры для закупки лекарственных препаратов; оценена ценовая эффективность используемых при закупке лекарств процедур.

Выводы. Процедура аукциона выбирается заказчиком чаще в условиях высокой конкуренции, низкой ценности и стоимости качества, более низкого рейтинга больницы, при этом выбирается в среднем менее опытный поставщик. Уровень закупочных цен выше в условиях выбора заказчиком процедуры единственного поставщика, большего уровня конкуренции; более высокой ценности качества закупаемого товара; выбора более опытного поставщика. Заказчикам удается достичь большего снижения цен в сравнении с НМЦК (а также в сравнении с розничными ценами) в условиях выбора процедуры аукциона, большего уровня конкуренции, более высокой ценности качества закупаемого товара, выбора менее опытного поставщика.

Ключевые слова: государственные закупки, электронный аукцион, конкуренция, лекарственные препараты.

\section{Введение}

Рынок государственных закупок включает в себя значительную долю всей торговли в стране: в 2018 г.доля закупок государственного сектора составила около 7,8 \% от объема ВВП. В связи с этим особое значение принимает повышение для заказчиков эффективности процедур госзакупок, достигаемое за счет снижения государственных расходов, улучшения доступа на рынок и повышения конкуренции, роста качества закупаемых товаров и услуг. Ключевой вопрос заключается в том, всегда ли общепринятая

(C) Жемкова А. М., 2020

Вестник ВГУ. Серия: Экономика и управление. 2020. № 3. C. $48-59$. процедура аукционов является наилучшим механизмом осуществления госзакупок?

Когда качество закупаемого товара принимает особое значение, простые ценовые критерии для определения поставщика, используемые при проведении электронных аукционов, могут оказаться неэффективными - это касается экспериментальных и доверительных товаров $^{1}$. При этом существуют два варианта реше-

${ }^{1}$ В классификации Нельсона [20] экспериментальные те товары, качество которых проверяется в процессе их эксплуатации; низкое качество товара зачастую можно обнаружить только спустя некоторое время их использования, кроме того, их достаточно сложно полностью специфицировать. Доверительные - товары, качество которых можно проверить только с помощью эксперта. 
ния проблемы: ex ante - установление четких спецификаций и требований качества товара, скоринговой оценки; ex post - мониторинг и контроль за исполнением уже после заключения контракта; при этом в обоих случаях стоит учитывать возможность возникновения коррупции. И в целом, если исходить из литературы, для закупки подобных (сложных) товаров предпочтительнее использовать процедуры, которые подразумевают проведение в том или ином виде переговоров, позволяющих раскрыть максимальное количество информации как организатору - о товаре, так и потенциальным поставщикам - об их возможностях и обязанностях.

Одна из наиболее длительных дискуссий в рамках исследования государственных закупок посвящена поиску ответа на вопрос «Аукцион или переговоры?». В данном случае аукцион, который представляет собой конкурентную процедуру, противопоставляется переговорам, которые могут являться проявлением монопольной власти заказчика. Традиционно предполагается (см. [1]), что аукцион обеспечивает более высокий уровень конкуренции, а следовательно, более низкую цену, а также эффективный, неискаженный выбор наилучшего поставщика. Однако зачастую поддерживается и продвижение альтернативных процедур, и в частности переговоров. Уилльямсон [2] и Голдберг [3] обозначили ключевые недостатки аукционов, которые особенно сильно проявляются в рамках осуществления сложных и долгосрочных контрактов, при которых особую ценность имеет информация не о цене, а о самом товаре, которую невозможно получить на этапе выбора поставщика. В результате заказчики могут столкнуться с проблемами в процессе исполнения контракта.

Манелли, Винсент [4] на основе расширенной теоретической модели закупок, в которых заказчик оценивает полезность приобретения товара по двум критериям: цене и качеству, продемонстрировали, что в ситуации, когда качество объекта закупки принимает особое значение, процедура последовательных переговоров имеет для заказчика большую эффективность, чем аукцион. Несмотря на то что в рамках аукциона выбирается поставщик, который потребует наименьших затрат от заказчика, это может привести к возникновению проблемы неблагоприятного отбора и к росту уже постконтрактных издержек. Тем не менее при закупке стандартных, простых товаров использование процедуры аукционов по-прежнему может считаться наиболее предпочтительным способом закупки. Таким образом, эффективность различных процедур может сильно различаться в зависимости от характеристик закупаемых товаров.

Неудивительно, что, исследуя госзакупки, авторы чаще всего обращаются к исследованию более неоднозначных, сложных товаров. Наиболее распространенными примерами таких закупок могут быть строительство и другие комплексные услуги (для которых характерно множество пунктов техзадания, постоянный контроль за исполнением контракта, неоднократные пост-переговоры, значительный объем работы раскрывается уже после заключения контракта, возможные задержки), автомобили и компьютеры (множество характеристик, сложность спецификации), а также лекарства и медицинские приборы (товары с сильно различающимся качеством даже для аналогичных товаров, жизненно важные товары).

К исследованию закупки медицинских препаратов обращаются Бонаккорси и др. [5]. Авторы утверждают, что проблема высокой ценности качества для столь сложного предмета закупки будет оказывать сильное влияние на выбор закупочной процедуры. При этом авторы разделяют закупки, исходящие от административного и медицинского персонала больниц, отталкиваясь от предположения, что для первых качество закупаемых товаров имеет меньше значения, чем цена; в то время как для вторых качество является более важным. Кроме этого, авторы ранжируют больницы по качеству оказываемых ими услуг, что является дополнительным критерием ценности качества. Авторы теоретически выводят ожидаемые полезности заказчика от покупки товара в случае выбора более и менее конкурентных закупочных процедур и затем сравнивают их между собой. На основе модели бинарного выбора между аукционом и переговорами авторы показали, что аукционы чаще выбирались, когда влияние медицинского персонала было низким, когда стоимость качества была высока, а его ценность низка, а также когда количество доступных поставщиков товара было ниже.

Къерстад [6], Гуччио и др. [7], Веллез [8] вслед за Бонаккорси и др. [5] продолжают исследование выбора оптимальных процедур для закупок медицинских товаров. Къерстад [6] анализирует опросные данные по закупкам больниц в Норвегии и приходит к выводу, что ни выбор процедуры, ни степень конкуренции не оказывает влияния на итоговые цены закупок. С другой стороны, Гуччио и др. [7], анализируя контракты, заключенные в рамках закупок итальянских больниц, обнаружили серьезное влияние выбо- 
ра процедуры на цены при условии экзогенного участия. Веллез [8] на аналогичной выборке контрактов итальянских больниц, но с предпосылкой об эндогенности конкуренции также показал, что использование процедуры переговоров никогда не приводит к более высоким ценам, чем использование аукциона. Кроме того, чем больше было участников переговоров, тем ниже были цены на переговорах в сравнении с аукционными. С другой стороны, продолжая тему ценовой эффективности процедур сложных закупок, Лалив, Шмутцлер [9] показали, что в контрактах на железнодорожные перевозки в Германии средние цены, установленные в результате аукционов, ниже.

Ценовая эффективность процедуры закупок в форме аукционов в эмпирике также проверяется в сравнении с рыночными ценами. На основе данных по закупкам Министерства сельского хозяйства США МакДональд и др. [10] показали, что цены, установленные в результате проведения аукционов, оказались значительно ниже, чем оптовые цены на те же продукты на частном рынке. Кроме этого, в работе было проверено влияние конкуренции на уровень закупочных цен: с ростом количества участников цены в среднем становились ниже, однако эффект сокращался по мере роста участников.

Бажари и др. [11] оценили влияние сложности спецификации проекта, конкуренции и ценности репутации исполнителя контракта на выбор заказчиком закупочной процедуры на основе данных по строительным контрактам. Сложность заказа оценивалась авторами по трем параметрам: стоимости проекта, площади (объему) работ и количеству подпунктов технического задания. Авторы показали, что существует сильная положительная связь между закупкой простых товаров и выбором конкурентных торгов, и напротив - между закупкой сложных и выбором процедуры переговоров. Кроме этого, была обнаружена связь между более высокой конкуренцией участников и выбором процедуры аукциона, а также между выбором переговоров и присуждением контракта более авторитетному и надежному подрядчику.

Вывод о предпочтительности для заказчика переговоров при закупке сложных товаров был также получен в работах Естаче [12], Чонг и др. [13], Леффлер и др. [14].

В российской академической литературе интерес к изучению рынка госзакупок зародился в результате реформирования системы в 2005 г. Яковлев и др. [15] оценивали ценовую эффективность процедур закупки простого то- вара (сахарного песка). В работе Бальсевич и др. [16] оценивается качество информации и уровень прозрачности, предоставляемый в рамках закупочной деятельности. Бальсевич, Подколзина [17] исследуют причины низкой конкуренции на рынке госзакупок в России и оценивают ее влияние на эффективность закупок бензина в пяти регионах за 2011-2013 гг. Островная, Подколзина в работе [18] анализируют причины фаворитизма и ограничения конкуренции в госконтрактах на основе анализа закупок лекарств в Санкт-Петербурге, а также меры, предпринимаемые для борьбы с ним. В работе Островной, Подколзиной [19] делается акцент на электронных аукционах: авторы изучают, как на эффективность электронных аукционов может влиять коррумпированный посредник.

Таким образом, результаты теоретических и эмпирических работ свидетельствуют о том, что для простых и стандартизированных товаров аукцион действительно является наиболее эффективной и надежной процедурой для отбора лучшего поставщика, однако он не всегда работает для сложных товаров, для которых особое значение принимают качественные критерии. Можно предположить, что в России для закупки сложных товаров, в том числе лекарственных препаратов, неконкурентные процедуры также могут оказаться более предпочтительными для заказчиков, чем общепринятые конкурентные (аукционы).

В этой связи данная статья ставит целью проверить, действительно ли аукционы могут оказаться не самой предпочтительной для заказчика процедурой закупки сложных товаров. Для этого в работе будет проведена оценка факторов (в том числе качественных характеристик товара и отношения заказчика к качеству), связанных с выбором заказчиком той или иной закупочной процедуры, и далее - анализ влияния этих факторов и выбора процедуры на уровень закупочных цен.

В статье мы будем концентрироваться на закупках лекарственных препаратов как одних из самых сложных товаров, качество которых, во-первых, представляет особую ценность для заказчика, а во-вторых - сложно проверить в момент приобретения. Кроме того, выбор данного товара для анализа обусловливается доступностью некоторых дополнительных данных, позволяющих лучше специфицировать параметры модели. Эти данные позволят описать отношение к качеству заказчика (больницы), а также сравнить закупочные цены со среднерыночными. В качестве же основного источника данных для анализа будет использована единая инфор- 
мационная система в сфере госзакупок², содержащая информацию по всем контрактам, товарам, их заказчикам и поставщикам.

\section{Материалы и методы исследования}

Особенности и структура закупочной деятельности в России

С 2010 г. в стране началась реформация системы государственных закупок в целях повышения эффективности исполнения бюджетов в области цены, качества и быстроты поставки товаров или осуществления услуг; повышения уровня прозрачности и доступности, привлечения более широкого спектра поставщиков, обеспечения более конкурентной среды. Одними из важнейших направлений реформации стали продвижение контрактной системы в сфере госзакупок и повышение их прозрачности, для чего была создана единая информационная система в сфере закупок, являющаяся агрегированным источником информации как по проведенным закупкам, так и планам-графикам закупок, заключенным контрактам и договорам и прочее.

В проведенном исследовании мы концентрировались только на закупках государственного сектора и бюджетных учреждений. В со-

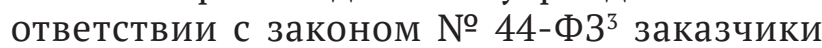
могут использовать два способа закупки:

- конкурентная закупка;

- закупка у единственного поставщика.

При этом конкурентная закупка может принимать множество форм: электронный аукцион (в 2018 г. аукционы составили 60 \% от общего количества закупок; победитель определяется исключительно по ценовому критерию), запрос котировок (наиболее простая и быстрая форма, с ограничением максимальной стоимости закупки), различные виды конкурсов (применяются для сложных проектов, требуют значительного объема конкурсной документации и времени, поскольку в условия контракта включаются качественные и другие критерии) и прочие форматы. Закупки у единственного поставщика находятся на втором месте по популярности, составляя в 2018 г. 23 \% от общего количества закупок.

Закупочные процедуры в российской практике достаточно сильно отличаются от приня-

\footnotetext{
${ }^{2}$ Единая информационная система в сфере закупок. URL: zakupki.gov.ru

${ }^{3} \mathrm{O}$ контрактной системе в сфере закупок товаров, работ, услуг для обеспечения государственных и муниципальных нужд: федер. закон от 5 апреля 2013 г. № 44Ф3 (последняя редакция).
}

тых в западных странах. Таким образом, в России отсутствует процедура «переговоров», которая является неконкурентным противовесом к процедуре аукциона в большинстве западных эмпирических исследований. Более или менее сопоставимой с переговорами процедурой в России является «закупка у единственного поставщика», в которой конкуренции нет в принципе.

Многие закупки оказываются несостоявшимися - в 2018 г. таких закупок было 36 \%. Из них для 17 \% был заключен контракт с единственным поставщиком. Возможными причинами несостоявшихся закупок можно назвать неадекватное установление и обоснование начальной цены (далее - НМЦК), некорректное описание объекта закупки, манипуляции с документацией; отсутствие конкуренции на рынке товара. Все эти факторы могут расцениваться поставщиками как маркер потенциально недобросовестного поведения. Стоит отметить, что наибольшее количество несостоявшихся закупок пришлось именно на сложные товары, в том числе на лекарственные препараты и медицинские приборы, закупаемые путем электронного аукциона. При этом наибольший процент состоявшихся закупок принадлежал конкурсным процедурам. Это также может свидетельствовать о более низкой эффективности аукционов для закупки сложных товаров в сравнении с неконкурентными или более сложными процедурами.

\section{Теоретическая модель и гипотезы для анализа}

На первом этапе анализа необходимо было понять, какие факторы могут оказаться связаны с выбором заказчиком процедуры для закупки лекарств. В предложенной модели заказчик выбирает между более и менее конкурентной процедурой закупки: электронным аукционом и закупкой у единственного поставщика. В случае выбора конкурентных процедур, если исходить из теории, будет приобретен товар по наименьшей цене, но и с наименьшим качеством, поскольку в рамках аукциона нет возможности задокументировать качественные критерии. При выборе неконкурентной процедуры у заказчика есть возможность отобрать поставщика товара с предпочитаемым качеством.

Лекарственные препараты - это сложный товар с сильно различающимся качеством даже внутри узких кодов ОКПД2; в то же время его качество может оказывать влияние на 
жизнь и здоровье людей, в связи с чем ключевое предположение исследования заключается в том, что ценность качества закупаемого товара, а также то, как заказчик оценивает важность критерия качества в сравнении с его ценой, будет тесно связано с выбором закупочной процедуры. Первую, и основную, гипотезу можно сформулировать следующим образом.

Гипотеза 1. Конкурентные по цене процедуры менее предпочтительны для заказчика, когда ценность качества товара высока и когда качество товара для заказчика важнее цены.

Также на основе обзора литературы выдвигаются две дополнительные гипотезы.

Гипотеза 2. Более конкурентные процедуры предпочтительнее для заказчиков в условиях высокой стоимости качества товара.

Гипотеза 3. Для закупки лекарств при росте конкуренции поставщиков чаще предпочитаются неконкурентные процедуры.

Для проверки гипотез, вслед за Бонаккорси и др. [5], будет оцениваться модель бинарного выбора заказчика между конкурентной и неконкурентной процедурой, зависимой переменной в которой выступает вероятность выбора той или иной процедуры, рассчитанная по количеству этих процедур в исходной выборке. Модель представлена в следующей форме:

$$
\begin{gathered}
\rho(\mathrm{TYPE})=\beta_{1} \ln Q+\beta_{2} \ln N+\beta_{3} q+ \\
+\beta_{4} R_{Z}+\beta_{5} E X P_{Z}+\beta_{6} E X P_{P}+\beta_{7} R_{P 1}+ \\
+\beta_{8} T I M E+\beta_{9} C+\text { const }
\end{gathered}
$$

где TYPE - тип процедуры (0 - аукцион; 1 единственный поставщик); $\rho$ - вероятность выбора той или иной процедуры; $Q$ - объем поставки; $N$ - количество доступных поставщиков товара группы; $q$ - разница в качестве товаров внутри группы; $R_{Z}$ - рейтинг больницы; $E X P_{Z}$ - опыт заказчика; $E X P_{P}$ - опыт поставщика; $R_{P}$ - рейтинг поставщика, измеренный по объему выручки; TIME - длительность контракта; $C$ - стоимость качества товара; const - константа. Как видно из формулы, помимо обозначенных в гипотезах параметров, в модель были включены показатели объема закупки (для контроля) и опыта поставщика, который тоже может свидетельствовать о более высоком качестве его товара.

Вторая часть анализа посвящена оценке ценовой эффективности используемых процедур для заказчика в зависимости от уже перечисленных факторов и выбранного типа процедуры. Для анализа будет использоваться три спецификации, в которых изменяется зависи- мая переменная - сама цена $(P)$; ее отклонение от рыночной $\left(\Delta P_{1}\right)$; снижение цены в сравнении с НМЦК $\left(\Delta P_{2}\right)$. Зависимые переменные сохраняются неизменными для всех трех спецификаций; форма оцениваемого уравнения регрессии представлена в формуле (2):

$$
\begin{gathered}
\rho\left(\Delta P_{1,2}\right)=\beta_{1} T I M E+\beta_{2} \ln Q+\beta_{3} \ln N+ \\
+\beta_{4} T I M E+\beta_{5} q+\beta_{6} R_{Z}+\beta_{7} E X P_{Z}+ \\
+\beta_{8} E X P_{P}+\beta_{9} R_{P 1}+\text { const }
\end{gathered}
$$

где TYРE - тип процедуры (0 - аукцион; 1 - единственный поставщик); $\rho$ - вероятность выбора той или иной процедуры; $Q$ - объем поставки; $N$ - количество доступных поставщиков товара группы; $q$ - разница в качестве товаров внутри группы; $R_{Z}$ - рейтинг больницы; $E X P_{Z}-$ опыт заказчика; $E X P_{P}$ - опыт поставщика; $R_{P 1}$ - рейтинг поставщика, измеренный по объему выручки; TIME - длительность контракта; const константа.

Общим предположением для второй модели является то, что неконкурентные процедуры для закупки сложных товаров могут оказаться более выгодными для заказчика за счет экономии средств - это может следовать как из теории, так и из выводов аналогичных исследований (см., например, [8]). Таким образом, в рамках анализа приведенной модели будут проверяться следующие гипотезы.

Гипотеза 4. Для выбора процедуры аукциона в среднем характерен более высокий уровень цен и меньшее снижение цены в сравнении с начальной и рыночной.

Гипотеза 5. В условиях высокой конкуренции поставщиков лекарств устанавливаются более высокие цены и меньшее снижение цен.

Гипотеза 6. Уровень цен при высокой ценности и предпочтении качества перед ценой, а также при выборе более опытного и надежного поставщика выше.

Для проверки поставленных гипотез была сформирована выборка по более чем семи тысячам закупок лекарств, проведенных в 2017-2018 гг. российскими больницами и другими профильными учреждениями. Первоначальная выборка содержала данные по 20 тысячам закупок, с условием их завершенности, проведенных с использованием двух процедур: электронного аукциона и закупки у единственного поставщика. Однако далее выборка урезалась из-за нечетких формулировок закупаемого товара (ситуация 1: предмет закупки - «поставка лекарственных средств» без конкретизации, с указанием широкого кода ОКПД; ситуация 2: объем за- 
купки равен единице, соответственно, невозможно выявить цену за единицу товара).

В табл. 1. представлено описание используемых переменных для обеих моделей, а также объясняются прокси, выбранные для описания ненаблюдаемых показателей качества и отношения к качеству заказчика.

\section{Обсуждение результатов}

Поскольку использование логит-регрессии не позволяет интерпретировать предсказанные значения коэффициентов, а только направление зависимости, дополнительно были рассчитаны предельные эффекты в средней точке для каждого параметра (табл. 2).

Т а бл и ц а 1

Закупки лекарственных препаратов: описательная статистика переменных за 2017-2018 г2.

\begin{tabular}{|c|c|c|c|c|c|c|}
\hline $\begin{array}{c}\text { Обозна- } \\
\text { чение }\end{array}$ & Переменная & $\begin{array}{l}\text { Число } \\
\text { набл. }\end{array}$ & $\begin{array}{c}\text { Сред- } \\
\text { нее }\end{array}$ & $\begin{array}{c}\text { Ст. } \\
\text { откл. } \\
\end{array}$ & Мин. & Макс. \\
\hline TYPE & $\begin{array}{l}\text { Способ закупки (0 - электронный аукцион; } 1 \text { - единственный } \\
\text { поставщик) }\end{array}$ & 7297 & 0,29 & 0,45 & 0 & 1 \\
\hline Q & бъем закупки (лог) & 7297 & 3,49 & 2,16 & 0 & 11,95 \\
\hline $\mathrm{P}$ & Итоговая цена закупки (лог) & 7297 & 8,65 & 2,24 & 2,59 & 16,54 \\
\hline$\Delta P$ & Отклонение цены от НМЦК (лог) & 2503 & $-2,64$ & 3,14 & $-19,59$ & 4,69 \\
\hline$\triangle P 2$ & Отклонение цены от рыночной ${ }^{4}$ (лог) & 2208 & 5,16 & 1,55 & $-0,86$ & 8,44 \\
\hline $\mathrm{N}$ & $\begin{array}{l}\text { Уровень конкуренции (количество поставщиков товара груп- } \\
\text { пы, когда-либо принимавших участие в госзакупках в разрезе } \\
\text { ОКПД2, лог) }\end{array}$ & 7297 & 7,09 & 0,83 & 0 & 7,5 \\
\hline $\mathrm{q}$ & $\begin{array}{l}\text { Ценность качества товаров (отношение цены конкретного } \\
\text { товара к средней по группе, лог) }\end{array}$ & 7297 & $-0,27$ & 1,36 & $-7,76$ & 3,28 \\
\hline $\mathrm{C}$ & $\begin{array}{l}\text { Стоимость качества товара (отношение средней по группе } \\
\text { цены товаров к средней по всем закупаемым лекарствам, лог) }\end{array}$ & 7297 & $-0,23$ & 0,68 & $-3,42$ & 1,52 \\
\hline $\operatorname{EXP}_{\mathrm{P}}$ & $\begin{array}{l}\text { Опыт поставщика (количество раз, когда поставщик } \\
\text { принимал участие в закупках в рамках выборки) }\end{array}$ & 7297 & 3,84 & 1,27 & 0 & 5,79 \\
\hline $\mathrm{EXP}_{\mathrm{Z}}$ & $\begin{array}{l}\text { Опыт заказчика (количество раз, когда заказчик принимал } \\
\text { участие в закупках в рамках выборки) }\end{array}$ & 7297 & 2,94 & 1,24 & 0 & 5,35 \\
\hline TIME & $\begin{array}{l}\text { Длительность контракта (количество дней между заключе- } \\
\text { нием контракта и его завершением, лог) }\end{array}$ & 7297 & 4,82 & 0,83 & 2,07 & 6,18 \\
\hline $\mathrm{R}_{\mathrm{z}}$ & $\begin{array}{l}\text { Рейтинг госпиталя } 5 \text { (прокси для отношения заказчика к ка- } \\
\text { честву, предпочтение качества перед ценой) }\end{array}$ & 7297 & 56,8 & 15,4 & 0 & 75 \\
\hline $\begin{array}{l}R_{\mathrm{P} 1} \\
R_{\mathrm{P} 2}\end{array}$ & $\begin{array}{l}\text { Рейтинг поставщика }{ }^{6}(1-\text { логарифм выручки поставщика; } \\
2 \text { - индекс платежеспособности) }\end{array}$ & $\begin{array}{l}7297 \\
7297\end{array}$ & $\begin{array}{c}22,05 \\
3,5\end{array}$ & $\begin{array}{l}0,85 \\
1,28\end{array}$ & $\begin{array}{c}18,4 \\
0\end{array}$ & $\begin{array}{l}26,8 \\
5,59\end{array}$ \\
\hline
\end{tabular}

Примечание: источник - расчеты автора на основе данных ЕИС, если не указано иное.

Т а бл и ц а 2

Закупки лекарственных препаратов: результаты оценки модели для выбора процедуры

\begin{tabular}{|l|c|}
\hline \multicolumn{1}{|c|}{ Зависимая переменная } & Коэффициент \\
\hline 1. Объем закупки & $-0,05^{* * * *}(0,005)$ \\
\hline 2. Количество доступных поставщиков & $0,05^{* * * *}(0,008)$ \\
\hline 3. Ценность качества & $0,03^{* * * *}(0,007)$ \\
\hline 4. Рейтинг больницы & $0,03^{* * * *}(0,003)$ \\
\hline 5. Опыт заказчика & $0,08^{* * * *}(0,009)$ \\
\hline 6. Опыт поставщика & $0,08^{* * * *}(0,016)$ \\
\hline 7. Рейтинг поставщика & - \\
\hline 8. Длительность контракта & $-0,06^{* * * *}(0,01)$ \\
\hline 9. Стоимость качества товара & $0,08^{* * * *}(0,007)$ \\
\hline сопь & $0,8^{* * * *}$ \\
\hline Psеuдо R 2 & 0,29 \\
\hline Количество наблюдений & 5325 \\
\hline
\end{tabular}

Примечание: источник - составлено автором; *** $\mathrm{p}<0,01,{ }^{* *} \mathrm{p}<0,05,{ }^{*} \mathrm{p}<0,1$ ****.

\footnotetext{
${ }^{4}$ Источник данных о рыночных ценах: Государственный реестр лекарственных средств. URL: grls.rosminzdrav.ru

${ }^{5}$ Источник: Казначейство России - Информация о государственных учреждениях. URL: bus.gov.ru

${ }^{6}$ Источник: База Руслана. URL: https://ruslana.bvdep.com/
} 
Итак, изначально были сделаны три предположения касательно характера связи между выбором типа процедуры и объясняющими переменными. В результате проведенной оценки, в соответствии с поставленными гипотезами, были получены следующие результаты:

- аукционы оказались менее предпочтительны для заказчика в условиях, когда качество товара ценится высоко, а также когда оно имеет большее значение, чем цена (параметр рейтинг госпиталя). Такой результат соответствует выводам, полученным в работе Бонаккорси и др. [5], Бажари и др. [11], Естаче [12], Чонг и др. [13], Леффлер и др [14]. Высокая ценность качества товаров означает и высокую дифференциацию цен в рамках группы, а значит, вероятность того, что в ходе аукционного отбора будет поставлен низкокачественный товар достаточно высока, что повышает предпочтительность неконкурентных процедур. Высокий рейтинг больницы требует поддержания репутации на определенном уровне, что включает в себя, помимо прочего, проведение эффективного лечения, которое требует высококачественных препаратов. При этом процедура аукциона не гарантирует поставки наиболее качественного товара;

- выбор аукционов был менее предпочтителен при высоком уровне конкуренции доступных поставщиков товара, что соответствует логике закупки сложных товаров. Чем больше поставщиков на рынке, тем меньше вероятность, что в ходе аукциона победит поставщик, способный поставить более качественный товар. Однако Бажари и др. [11] пришли к противоположному выводу, утверждая, что в условиях высокой конкуренции чаще выбирается процедура аукциона;

- отвергается гипотеза, утверждающая, что выбор аукционов будет осуществляться чаще в условиях более высоких издержек фирм на поставку качественного продукта - как видно из табл. 1, стоимость качества продукции была положительно связана с выбором неконкурентной процедуры. Таким образом, заказчики предпочитают использовать процедуру единственного поставщика для закупки сравнительно более дорогих групп товаров и аукционов - для дешевых;

- кроме этого, выбор заказчиками лекарственных препаратов процедуры аукциона оказался связан с большим объемом закупки, меньшим опытом заказчика в проведении закупок, а также выбором менее опытного поставщика - данный вывод соответствует результатам предыдущих исследований. Выбор процедуры единственного поставщика предполагает, что стороны уже обладают определенным набором связей и знают заранее, с кем бы конкретно хотели заключить договор на поставку. При этом рейтинг поставщика, измеренный по логарифму его выручки, оказался незначим при выборе процедуры. Это может быть обоснованно для рынка лекарственных препаратов, для которого высокая финансовая успешность поставщика совершенно не отражает качество поставляемой продукции и не так важна для поставки. Кроме этого, выбор процедуры единственного поставщика был связан с более краткосрочными контрактами на поставку. Высокая срочность может свидетельствовать о необходимости как высококачественного товара, так и использования упрощенной процедуры.

Результаты оценивания второй модели в трех спецификациях методом OLS представлены в табл. 3.

Из оценки второй модели можно сделать следующие выводы: во-первых, в среднем процедура аукциона оказалась связана с более низкими итоговыми ценами, кроме того, аукцион позволял добиться большего снижения итоговой цены в сравнении с начальной. При этом аукцион давал меньше преимуществ перед рыночной ценой в сравнении с процедурой единственного поставщика. Это противоречит гипотезе 4, однако соответствует результатам некоторых аналогичных исследований по другим странам (см., например, [6; 9]. С другой стороны, Гуччио и др. [7], Веллез [8] пришли к противоположным выводам). Высокий уровень конкуренции действительно оказался связан с более высокими ценами, однако позволял сильнее снизить цены в результате торгов или переговоров в сравнении с начальными и рыночными. Последняя гипотеза - касательно предпочтения и ценности качества товаров соответствовала полученным результатам лишь отчасти: например, если более качественные товары были ожидаемо связаны с более высокой ценой и, одновременно, большим снижением цен, то предпочтение качества (измеренное прокси - рейтингом госпиталя) не оказывало никакого влияния на цены в принципе. Опыт заказчика способствовал более низким ценам и меньшему снижению цены в сравнении с рыночной, в то время как опыт поставщика был связан только с меньшим снижением цены в сравнении с рыночной и большей в сравнении с НМЦК. Рейтинг постав- 
Модель выбора процедуры государственных закупок на примере лекарственных препаратов

Т а бл и ц 3

Закупки лекарственных препаратов: результаты оценки модели для сравнения ценовой эффективности процедур

\begin{tabular}{|l|c|c|c|}
\hline \multicolumn{1}{|c|}{ Зависимая переменная } & Р (цена) & Р от начальной & Р от среднерыночной \\
\hline Тип процедуры & $0,26^{* * * *}(0,03)$ & $-0,2^{* * * * *}(0,08)$ & $-0,15^{* * * *}(0,05)$ \\
\hline Объем закупки & $-0,12^{* * * * *}(0,007)$ & $0,89^{* * * *}(0,06)$ & $1,06^{* * * *}(0,04)$ \\
\hline $\begin{array}{l}\text { Количество доступных по- } \\
\text { ставщиков товара группы }\end{array}$ & $0,218^{* * * *}(0,01)$ & $0,11^{* *}(0,03)$ & $0,13^{* * * *}(0,06)$ \\
\hline Длительность контракта & $-0,03^{*}(0,014)$ & - & - \\
\hline Ценность качества & $0,65^{* * * *}(0,01)$ & $0,66^{* * * *}(0,14)$ & $0,65^{* * * *}(0,22)$ \\
\hline Рейтинг госпиталя & - & - & - \\
\hline Опыт заказчика & $-0,013^{* * * *}(0,005)$ & - & $-0,007^{* * * *}(0,002)$ \\
\hline Опыт поставщика & - & $0,05^{* * *}(0,02)$ & $-0,02^{* * *}(0,009)$ \\
\hline Рейтинг поставщика & $-0,001^{* *}(0,0006)$ & $-0,006^{* *}(0,003)$ & $0,02^{*}(0,01)$ \\
\hline Особые условия (МСП) & - & - & - \\
\hline сопл & $4,85^{* * * * *}$ & $4,6^{* * * *}(0,47)$ & $4,09^{* * * *}(0,3)$ \\
\hline $\mathrm{R}^{2}$ & 0,66 & 0,74 & 0,69 \\
\hline Количество наблюдений & 2502 & 2502 & 2023 \\
\hline
\end{tabular}

Примечание: источник - составлено автором; *** $\mathrm{p}<0,01,{ }^{* *} \mathrm{p}<0,05,{ }^{*} \mathrm{p}<0,1$ ***.

щика, измеренный по логарифму его выручки, был связан с более низкими ценами, большей разницей с рыночной ценой и меньшей разницей с НМЦК, что может объясняться наличием эффекта масштаба в производстве.

\section{Заключение}

В работе была поставлена цель оценить предпочтительность для государственных заказчиков различных процедур закупки лекарственных препаратов в российских больницах. Как показывает и теория, и практика, аукцион не всегда является наиболее эффективной процедурой для закупки сложных товаров (а лекарства, безусловно, являются очень сложным товаром). В результате оценки модели для выбора закупочной процедуры, а также модели ценовой эффективности существующих способов закупки были получены следующие выводы:

- процедура аукциона выбиралась заказчиком чаще в условиях высокой конкуренции, низкой ценности и стоимости качества, более низкого рейтинга госпиталя (низкого предпочтения качества перед ценой), при этом выбирался в среднем менее опытный поставщик;

- уровень закупочных цен был выше в условиях выбора заказчиком процедуры единственного поставщика, большего уровня конкуренции; более высокой ценности качества закупаемого товара; выбора более опытного поставщика;

- заказчикам удавалось достичь большего снижения цен в сравнении с НМЦК (а также в сравнении с розничными ценами) в условиях выбора процедуры аукциона, большего уровня конкуренции, более высокой ценности качества закупаемого товара, выбора менее опытного поставщика.

Таким образом, на основе проведенного исследования можно утверждать, что для закупки лекарств, в среднем, процедура аукционов оказывается менее предпочтительной для заказчика, несмотря на наличие ценовой выгоды. Особенно это характерно для ситуации, когда качество высоко ценится заказчиком, а товары сильно различаются по качеству даже внутри узких групп препаратов. Заказчики готовы переплачивать, выбирая неконкурентные процедуры, если смогут повысить свою уверенность в том, что им будет поставлены более качественные препараты. Для таких закупок повышен риск выбора недобросовестного поставщика в ходе аукциона, который предложит более низкую цену, но потенциально окажется не способен поставить достаточно качественный товар.

Нельзя не упомянуть дальнейшие направления развития работы. В данной статье в качестве примера сложных поставок рассматриваются закупки только одного товара. Однако полученные выводы нельзя экстраполировать на все сложные товары, поскольку каждые из них могут иметь свои особенности. Таким образом, стоит расширить исследование, включив в анализ других групп закупочных товаров - 
более стандартизированных, или, наоборот, комплексных, с более низкой или высокой долей неопределенности. Другим направлением развития работы может стать борьба с эндогенностью, которая должна быть учтена в том числе при использовании в анализе фактора конкуренции (количества участников), также зависящего от цены закупки и принятых форматов процедур. Наконец, исследование можно расширить, включив в него также анализ причин возможной неэффективности закупок и провалов рынка в зависимости от типа товара и формата процедур.

\section{Источник финансирования}

Данное исследование проведено при поддержке Института прикладных экономических исследований Российской академии народного

\section{Библиографический список}

1. Bulow J., Klemperer P. Auctions versus Negotiations // American Economic Review. 1996. Vol. 86, no. 1. P. 180-194.

2. Williamson O. Franchise Bidding for Natural Monopolies-In General and with respect to CATV // Bell Journal of Economics. 1976. Vol. 7, no. 1.P. 73-104.

3. Goldberg V. P. Competitive Bidding and the Production of Precontract Information // Bell Journal of Economics. 1977. Vol. 8. P. 250-261.

4. Manelli A., Vincent D. Optimal Procurement Mechanism//Econometrica. 1995.Vol.63. P. 591-620.

5. Bonaccorsi A., Lyon T. P., Pammolli F., Turchetti G. Auctions vs. Bargaining: An Empirical Analysis of Medical Device Procurement // LEM Working Paper Series. 2000. P. 1-17.

6. Kjerstad. Auctions vs negotiations: a study of price differentials // Econometrics and Health Economics. 2005. Vol. 14, no. 12. P. 1239-1251.

7. Guccio C., Pignataro G., Rizzo I. Efficiency of procurement procedures for medical devices // Rivista di Politica Economica. 2006.

8. Vellez M.Auctions versus Negotiations: Evidence from Public Procurement in the Italian Healthcare Sector // CEIS Tor Vergata Research paper series. 2011. Vol. 9 (4), no. 191.

9. Lalive R., Schmutzler A. Auctions vs Negotiations in Public Procurement Which Works Better? // University of Zurich, Department of Economics Working Paper Series. 2011. Vol. Working Paper № 23.

10. MacDonald J. M., Handy C. R., Plato G. E. Competition and Prices in USDA Commodity Procurement // Southern Economic Journal. 2002.Vol.6, no. 1.P.128-143.

11. Bjari P., McMillan, Tadelis S. Auctions Versus Negotiations in Procurement: An Empirical Analysis // The Journal of Law, Economics and Organization. 2009. Vol. 25, no. 2. P. 372-399. хозяйства и государственной службы при Президенте Российской Федерации.

\section{Благодарности}

Автор выражает благодарность сотрудникам Центра исследований отраслевых рынков Института прикладных экономических исследований Российской академии народного хозяйства и государственной службы при Президенте Российской Федерации за полезные советы при подготовке данной работы, за помощь в сборе, обработке и анализе данных.

\section{Конфликт интересов}

Автор декларирует отсутствие явных и потенциальных конфликтов интересов, связанных с публикацией настоящей статьи.

12. Estache A., Guasch J. L., Iim, A., Trujillo L. Multidimensionality and renegotiation: Evidence from transport-sector public-private-partnership transactions in Latin America // Review of Industrial Organization. 2009. Vol. 35, no. 1-2. P. 41.

13. Chong E., Staropoli C., Yvrande-Billon A. Auction versus Negotiation in Public Procurement: Looking for New Empirical Evidence 2009.

14. Leffler K. B., Rucker R. R., Mann I. A. The choice among sales procedures: Auction v. negotiated sales of private timber. Montana State University, Department of Agricultural Ecoomics and Economics. 2008.

15. Яковлев А. А., Башина А. С., Демидова О. А. Анализ эффективности способов закупки простого однородного товара (на примере сахарного песка) // Экономический журнал ВШЭ. 2013. № 4. C. 649-677.

16. Бальсевич А. А., Пивоварова С. Г., Подколзина E. A. Роль прозрачности информации в государственных закупках: пример российских регионов // Журнал Новой экономической ассоциации. 2012. T. 3, № 15. C. 82-112.

17. Бальсевич А. А., Подколзина Е. А. Причины и последствия низкой конкуренции в государственных закупказ в России // Экономический журнал ВШЭ. 2014. № 4. С. 563-585.

18. Островная М., Подколзина Е. Снижение эффективности аукционов и борьба с ограничением конкуренции в государственных закупках // Вопросы экономики. 2014. № 11. С. 41-57.

19. Островная М.В., Подколзина Е. А. Электронные аукционы и фаворитизм в российских государственных закупках // Экономический журнал ВШЭ. 2014. № 4. С. 586-619.

20. Nelson P. Information and Consumer Behavior // Journal of Political Economy. 1970. Vol. 78, no. 2. P. 311-329. 
Модель выбора процедуры государственных закупок на примере лекарственных препаратов

Жемкова Александра Михайловна, научный сотрудник Центра исследований отрасле-

Поступила в редакцию 10.06.2020 вых рынков, Институт прикладных экономиПодписана в печать 10.09.2020 ческих исследований, Российская академия народного хозяйства и государственной службы при Президенте Российской Федерации, Москва, Российская Федерация

E-mail: zhemkova-am@ranepa.ru

ORCID ID: 0000-0002-0033-6028 


\section{Model of the choice of public procurement procedure on the example of medicines}

\section{A. M. Zhemkova ${ }^{1 凶}$}

${ }^{1}$ Institute for Applied Economic Research, Russian Presidential Academy of National Economy and Public Administration, Vernadsky prospect, 82, building 1, 119571, Moscow, Russian Federation

Cite as: Zhemkova, A. M. (2020) Model of the choice of public procurement procedure on the example of medicines. Proceedings of Voronezh State University. Series: Economics and Management. 3, 48-59. (In Russ., abstract in Eng.). DOI: $10.17308 /$ econ.2020.3/3104

Subject. The results of theoretical and empirical studies indicate that for simple and standardized goods, the auction is the most effective and reliable procedure for selecting the best supplier. However, when the quality of the purchased good is particularly important, simple price criteria used in electronic auctions for determining the supplier may be ineffective. The article evaluates the preference for customers (Russian hospitals) of procedures for the medicines procurement.

Objectives. The main objective of the study is to check whether auctions may turn out to be not preferable procedure for the customer for purchasing complex goods (for example, drugs) indeed. The study evaluates the factors (including the qualitative characteristics of the goods and the customer's attitude to quality) that affect the choice of the purchasing procedure by the customer, and then analyzes the influence of these factors and the choice of the procedure on the level of purchase prices.

Methodology. In the process of evaluating the effectiveness of procedures for the procurement of medicines, the authors use methods of qualitative and quantitative analysis. The empirical basis is collected from data from the site of the unified information system in the field of public procurement. Results. The authors provided an empirical analysis of the process of choosing a procedure for the medicines procurement by the customer, and evaluated the price effectiveness of the procedures used in the procurement of medicines.

Conclusion. The customer chose the auction procedure more often in conditions of high competition, low value and cost of quality, a lower hospital rating; in auction more often less experienced supplier is choosen. The level of purchase prices is higher when the customer chooses the procedure of a single supplier, when the competition is higher, the value of quality of the purchased goods is higher, and when a more experienced supplier is choosen. Customers manage to achieve a greater price reduction in comparison with the maximum bid (as well as in comparison with retail prices) when they choose the auction procedure, when the competition and value of the quality is higher, and when the less experienced supplier is choosen.

Keywords: government procurement, electronic auction, competition, pharmaceuticals.

\section{Source of financing}

The reported study was supported by the Institute of Applied Economic Research of the Russian Academy of National Economy and Public Administration

\section{Acknowledgments}

The author is grateful to the staff of the Center for Industrial Markets Research of the Institute of Applied Economic Research of the Russian Academy of Na-

\section{References}

1. Bulow J. \& Klemperer P. (1996) Auctions versus Negotiations. American Economic Review, 86 (1), 180-194.

2. Williamson O. (1976) Franchise Bidding for Natural Monopolies-In General and with respect to CATV. Bell Journal of Economics, 7 (1), 73-104. tional Economy and Public Administration for useful advices in the preparation of this paper, for assistance in collecting, processing and analyzing data.

\section{Conflict of Interest}

The authors declare the absence of obvious and potential conflicts of interest related to the publication of this article.

3. Goldberg V. P. (1977) Competitive Bidding and the Production of Precontract Information. Bell Journal of Economics. 8, 250-261.

4. Manelli A. \& Vincent D. (1995) Optimal Procurement Mechanism. Econometrica, 63, 591-620. 
5. Bonaccorsi A., Lyon T. P., Pammolli F., Turchetti G. (2000) Auctions vs. Bargaining: An Empirical Analysis of Medical Device Procurement. LEM Working Paper Series, 1-17.

6. Kjerstad, E. (2005). Auctions vs negotiations: a study of price differentials. Health economics, 14(12), 1239-1251.

7. Rizzo, C. G. G. P. I. (2006). Efficiency of procurement procedures for medical devices. Rivista di politica economica, 96(1-4), 135.

8. Vellez, M. (2011). Auctions versus negotiations: Evidence from public procurement in the Italian healthcare sector. CEIS Tor Vergata Research paper series, 9 (4), 191.

9. Lalive, R., \& Schmutzler, A. (2011). Auctions vs negotiations in public procurement: which works better? SSRNElectronic Journal. Available from: https:// ssrn.com/abstract=1919531.

10. MacDonald J. M., Handy C. R. \& Plato G.E. (2002) Competition and Prices in USDA Commodity Procurement. Southern Economic Journal, 6 (1), 128-143.

11. Bajari P., McMillan, R. \& Tadelis S. (2009) Auctions Versus Negotiations in Procurement: An Empirical Analysis. The Journal of Law, Economics and Organization, 25 (2), 372-399.

12. Estache, A., Guasch, J. L., Iimi, A. \& Trujillo, L. (2009) Multidimensionality and renegotiation: Evidence from transport-sector public-private-partnership transactions in Latin America. Review of Industrial Organization, 35 (1-2), 41.

13. Chong E., Staropoli C. \& Yvrande-Billon A. (2014) Auction versus Negotiation in Public Procure- ment: Looking for New Empirical Evidence. In Brousseau E., Glachant J-M. (eds.) The Manufacturing Markets, Legal, Political and Economic Dynamics, Cambridge University Press, pp. 120-142

14. Leffler K.B., Rucker R.R., Mann I.A. (2008) The choice among sales procedures: Auction v. negotiated sales of private timber. Montana State University, Department of Agricultural Economics and Economics.

15. Yakovlev A.A., Bashina A.S., Demidova O.A. (2013) [Analysis of the effectiveness of methods of purchasing a simple homogeneous product (on example of granulated sugar)]. Ekonomicheskii zhurnal VSE, 4, 649-677. (In Russian).

16. Balsevich A.A., Pivovarova S.G., Podkolzina E.A. (2012) [The role of information transparency in public procurement: the example of Russian regions]. Jurnal novoi ekonomicheskoi associacii, 3 (15), 82-112. (In Russian).

17. Balsevich A.A., Podkolzina E.A. (2014) [Causes and Consequences of Low Competition in Public Procurement in Russia]. Ekonomicheskii zhurnal VSE, 4, 563-585. (In Russian).

18. Ostrovnaya M., Podkolzina E. (2014) [Decrease in the efficiency of auctions and the fight against restricting competition in public procurement]. Voprosy economiki, 11, 41-57. (In Russian).

19. Ostrovnaya M.V., Podkolzina E.A. (2014) [Electronic auctions and favoritism in Russian public procurement]. Ekonomicheskii zhurnal VSE, 4, 586-619. (In Russian).

20. Nelson P. (1970) Information and Consumer Behavior. Journal of Political Economy, 78 (2), 311-329.

\footnotetext{
Aleksandra M. Zhemkova, Research Fellow, Center for Industrial Markets Research, Institute for Applied Economic Research, Russian Academy of National Economy and Public Administration, Moscow, Russian Federation

E-mail: zhemkova-am@ranepa.ru

ORCID ID: 0000-0002-0033-6028
} 